INTERNATIONAL JOURNAL
OFICAL SCIENCES
PHARMACEUTICAL
RESEARCH

Received on 24 July 2019; received in revised form, 05 April 2020; accepted, 17 April 2020; published 01 June 2020

\title{
FORMULATION AND EVALUATION OF CONTROLLED POROSITY OSMOTIC TABLET OF VERAPAMIL HYDROCHLORIDE
}

\author{
M. A. Shivnikar * and P. N. Bhong
}

Marathwada Mitra Mandal's College of Pharmacy, Off Kalewadi Phata-Pimpri Road, Thergaon, Pune 411033, Maharashtra, India.

Keywords:

Osmotic System,

Controlled porosity osmotic tablet, Pore formers, Wicking agent

\section{Correspondence to Author:}

\section{A. Shivnikar}

Assistant Professor,

Marathwada Mitra Mandal's College of Pharmacy, Off Kalewadi PhataPimpri Road, Thergaon, Pune 411033, Maharashtra, India.

E-mail: shivnikarmadhavi@gmail.com

\begin{abstract}
Verapamil hydrochloride is a water-soluble drug, so it is suitable to develop controlled porosity osmotic pump. As Verapamil $\mathrm{HCl}$ is a short-acting drug, so developed formulation provides the advantages of controlled release formulations. The developed formulation provides advantages of less steps of manufacturing procedure, no need for laser drilling, and economical, all of which made the procedure easily amenable to mass production using conventional tablet machines. Verapamil $\mathrm{HCl} 120 \mathrm{mg}$ core formulations were prepared coated with film former (cellulose acetate): pore former (sorbitol). The effect of different formulation variables, namely, membrane weight gain, and amount of pore former in the membrane, were studied. Verapamil $\mathrm{HCl}$ release was inversely proportional to the membrane weight (coating thickness) but directly related to the initial amount of pore former (sorbitol) in the membrane. Drug release from the developed formulations was independent of $\mathrm{pH}$ but dependent on the osmotic pressure of the release medium. Verapamil $\mathrm{HCl}$ release from the developed formulation follows zero-order. The drug release from formulation was proved as dependent on osmotic pressure only. Results of SEM studies showed the formation of pores in the membrane after coming in contact with aqueous dissolution fluid from where the drug release occurred. The manufacturing procedure was found to be reproducible, and formulations were stable after three months of accelerated stability studies.
\end{abstract}

\section{INTRODUCTION: For many decades,} conventional dosage forms, which are of prompt releasing nature, are used for the treatment of acute and chronic diseases. The conventional dosage forms provide no control over the release of the drug. Recently, several technical advancements have been made. These have resulted in the development of new techniques in drug delivery.

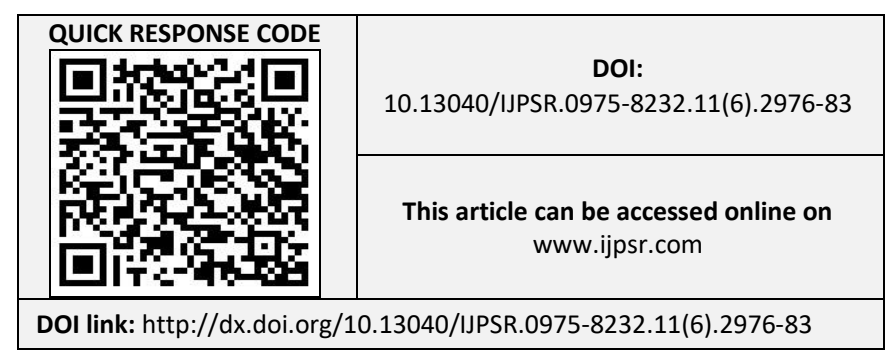

These techniques are capable of controlling the rate of drug delivery, sustaining the duration of therapeutic activity and/or targeting the delivery of the drug to tissue.

It is advantageous to deliver some drugs with a short half-life and which are to be given frequently for chronic ailments in the form of controlled release formulations. The majority of existing oral controlled release systems are matrix-based, and their principle drug release mechanism is based on drug diffusion through the matrix system. The diffusion is altered by the $\mathrm{pH}$ of the medium, the presence of food, hydrodynamic conditions, and the body's other physiological factors, all of which can cause difficulty in controlling the drug release rate 
and result in poor in-vivo - in-vitro correlations (IVIVC) $^{1,2}$.

The objective of the work is to release the drug from these osmotic systems independent of the physiological factors of the gastrointestinal tract $(\mathrm{pH})$ and to get zero-order drug release.

\section{Basic Components of Osmotic Systems:}

1. Drug

2. Osmogen

3. Semipermeable membrane

4. Coating solvents

5. Pore-forming agents

6. Plasticizers

MATERIALS AND METHODS: Verapamil $\mathrm{HCl}$, MCC, Magnesium Stearate, Talc, Sorbitol, Acetone, IPA, Cellulose Acetate were used in work done at Pad. Dr. D. Y. Patil College of Pharmacy, Akurdi, Pune.

Development of Analytical Method (UV Spectrophotometry): ${ }^{3}$ UV spectroscopic method is chosen for the analysis of Verapamil $\mathrm{HCl}$. The wavelength of $278 \mathrm{~nm}$ was selected for further study.

Optimization of Sodium Chloride in Core Tablet: ${ }^{4}$ Incorporating sodium chloride can modulate the release of drug within the system to control drug release. For the optimization of sodium chloride in the core tablet, preliminary formulations were prepared by incorporating sodium chloride into the core tablet in $10,15,20$, 25, 30, $40 \mathrm{mg}$. Increments. The tablets were prepared by direct compression technique. The ingredients were weighed accurately as per the formula given in Table 1. The ingredients were kneaded in the mortar and pestle for 15-20 min.

TABLE 1: OPTIMIZATION OF SODIUM CHLORIDE IN CORE TABLET

\begin{tabular}{ccccccc}
\hline Ingredients & \multicolumn{7}{c}{ Weight (mg) } \\
\cline { 2 - 7 } & D1 & D2 & D3 & D4 & D5 & D6 \\
\hline Verapamil & 120 & 120 & 120 & 120 & 120 & 120 \\
hydrochloride & & & & & & \\
Sodium chloride & 10 & 15 & 20 & 25 & 30 & 40 \\
Lactose & 20 & 20 & 20 & 20 & 20 & 20 \\
MCC & 143 & 138 & 133 & 128 & 123 & 118 \\
Mg stearate & 5 & 5 & 5 & 5 & 5 & 5 \\
Talc & 2 & 2 & 2 & 2 & 2 & 2 \\
Total Weight & 300 & 300 & 300 & 300 & 300 & 300 \\
\hline
\end{tabular}

The core tablets were compressed at an average weight of $300 \mathrm{mg}$ using $10 \mathrm{~mm}$ concave punches and $6-7 \mathrm{~kg} / \mathrm{cm}^{2}$ hardness in 8 stations rotary tablet machine.

\section{Coating Process:}

Preparation of Coating Solution: ${ }^{4,5}$ The coating solution containing cellulose acetate, sorbitol (pore former), and PEG 400 (plasticizer) was prepared as per the formula given in Table 2. Accurately weighed quantity of cellulose acetate was added to acetone $(70 \% \mathrm{w} / \mathrm{w})$. The mixture was stirred until the formation of a clear solution. The accurately weighed quantity of sorbitol $(25 \% \mathrm{w} / \mathrm{w}$ of the total weight of polymer) was firstly dissolved in a small quantity of deionized water and then mixed with IPA $(30 \% \mathrm{w} / \mathrm{w})$. The weighed quantity of PEG (5\% $\mathrm{w} / \mathrm{w}$ of the total weight of polymer) was added to the IPA $(30 \% \mathrm{w} / \mathrm{w})$ solution. The solution was then added slowly to the cellulose acetate solution. The mixture was stirred continuously for $30 \mathrm{~min}$.

TABLE 2: FORMULATION OF COATING SOLUTION

\begin{tabular}{cc}
\hline Ingredients & Concentration $(\% \mathbf{w} / \mathbf{w})$ \\
\hline Cellulose acetate & 4 \\
Sorbitol & 25 (of total wt. of polymer) \\
PEG 400 & 5 \\
Acetone : IPA & $70: 30$ \\
\hline
\end{tabular}

Dip Coating: 5 Tablets were coated by the dipcoating process. $4 \%$ cellulose acetate solution was used for coating. The coating solution was prepared as per the formula given in Table 2 . The coating of the core tablet was done manually by holding each tablet with the help of forceps. The coated tablets were dried by keeping them at room temperature for $24 \mathrm{~h}$. Weight gain maintained at $4 \% \mathrm{w} / \mathrm{w}$. The thickness of the coated tablets measured by using a digital Vernier caliper. The tablets were evaluated by studying the release study for $6 \mathrm{~h}$, in a $900 \mathrm{ml}$ dissolution medium using USP Apparatus 2 (Paddle) with $50 \mathrm{rpm}$.

Evaluation of Consistency of Coat: To study the consistency of coat, formulations were formulated using $\mathrm{NaCl}(30 \mathrm{mg}$ ) as an osmogen (excess of osmogen burst external coat). The tablet comprised of Verapamil hydrochloride $(120 \mathrm{mg})$, sodium chloride (30 mg), lactose (20 mg), MCC (123 mg), magnesium stearate $(5 \mathrm{mg})$ and talc $(2 \mathrm{mg})$.

The tablets were then coated with a coating composition, which was constant for the 
formulations Table 2 to get a weight gain of 3, 4, 5, 6, 7, and $8 \% \mathrm{w} / \mathrm{w}$ Table 3 . The tablets were evaluated by studying the consistency of coat for $8 \mathrm{hr}$, in $900 \mathrm{ml}$ dissolution medium using USP Apparatus 2 (Paddle) with $50 \mathrm{rpm}$. The consistency of the coat at various \% weight gains was summarized in Table 3.

TABLE 3: PRELIMINARY FORMULATIONS FOR EVALUATION OF CONSISTENCY OF COAT

\begin{tabular}{cc}
\hline Formulation Code & \% Weight Gain \\
\hline D1 & 3 \\
D2 & 4 \\
D3 & 5 \\
D4 & 6 \\
D5 & 7 \\
D6 & 8 \\
\hline
\end{tabular}

Evaluation of Osmotic Coated Tablets: ${ }^{6,7}$ Prior to the compression tablets, blends were evaluated for their bulk density and tapped density, and from these values, the \% compressibility and Hausner's ratio were calculated 6 . After compression, the tablets were evaluated for their hardness, thickness, and weight variation.

In-vitro Dissolution Test: ${ }^{8}$ Dissolution test for drug release study of formulations labeled extended-release of Verapamil $\mathrm{HCl}$ is carried out by Medium: Buffer of $\mathrm{pH} 7.5,900 \mathrm{ml}$.

Apparatus II: 50rpm

The Optimized Formulation was then Further Evaluated for Effect of Various Concentrations of Pore Forming Agent sorbitol: ${ }^{9}$ In order to study the effect of various concentration of pore former on in-vitro drug release, the tablets were coated with pore former $15 \% \mathrm{w} / \mathrm{w}, 20 \% \mathrm{w} / \mathrm{w}, 25 \%$ $\mathrm{w} / \mathrm{w}$ and the without pore former, the $\%$ weight gain of tablets were kept constant. The weight gain by the tablets was $5 \pm 0.5 \%$. Formulations were done as per the formula given in Table 4.

TABLE 4: FORMULATIONS FOR EVALUATION OF EFFECT OF PORE FORMER

\begin{tabular}{ccccc}
\hline Ingredients & \multicolumn{4}{c}{ Weight (mg) } \\
\cline { 2 - 5 } & F1 & F2 & F3 & F4 \\
\hline Verapamil HCl & 120 & 120 & 120 & 120 \\
MCC & 123 & 123 & 123 & 123 \\
$\mathrm{NaCl}$ & 30 & 30 & 30 & 30 \\
Lactose & 20 & 20 & 20 & 20 \\
Mg. stearate & 5 & 5 & 5 & 5 \\
Talc & 2 & 2 & 2 & 2 \\
Sorbitol (\% w/w) & 15 & 20 & 25 & - \\
\hline
\end{tabular}

Kinetics of Drug Release: ${ }^{10,11,20}$ The dissolution profile of all the formulations were fitted to zeroorder kinetics, first-order kinetics, Higuchi, Hixson-Crowell, Korsmeyer and Peppas to ascertain the kinetic modeling of drug release by using a PCP Disso Version 2.08 software, and the model with the higher correlation coefficient was considered to be the best model.

Effect of pH on Drug Release: ${ }^{12,} 13$ In-vitro dissolution studies were performed using USP Apparatus 2 (Paddle) in different release media (phosphate buffer $\mathrm{pH} 4,6.8$ ) maintained at $37{ }^{\circ} \mathrm{C} \pm$ $0.5^{\circ} \mathrm{C}$ and $50 \mathrm{rpm}$. The optimized formulation (F3) was selected for the study of the effect of $\mathrm{pH}$ on drug release. The responses were noted in triplicate.

Surface Morphology Study: ${ }^{14}$ To evaluate the surface morphology of the coating membrane, surfaces of the optimized formulation (F3) were examined using scanning electron microscopy both before and after dissolution (XL30 ESEM TMP+EDAX, Philips). Membranes were dried at $45^{\circ} \mathrm{C}$ for $12 \mathrm{~h}$ and stored between in a desiccator until examination.

Stability Study: ${ }^{15,16}$ The optimized formulation (F3), which gave desired zero-order release for an extended period of time was selected, packed in aluminum foil and subjected to stability studies as per ICH guidelines, $40 \pm 2{ }^{\circ} \mathrm{C}$ and $75 \pm 5 \% \mathrm{RH}$ (Thermolab). Samples were withdrawn at time intervals of 1,2 , and 3 months. The samples were evaluated for appearance, assay and in-vitro release profile.

Comparative Study of CPOP and EOP: ${ }^{17}$ The formulation for EOP comprised of Verapamil hydrochloride $(120 \mathrm{mg})$, sodium chloride $(30 \mathrm{mg})$, lactose $(20 \mathrm{mg})$, MCC (123 mg), magnesium stearate $(5 \mathrm{mg})$ and Talc $(2 \mathrm{mg})$ and coated with5\% weight gain (optimized level of factorial formulation was considered) without pore former (sorbitol). The new formulated tablets were drilled with mechanical drill. Orifice size $0.5 \mathrm{~mm}$ (F8), 0.8 $\mathrm{mm}$ (F9) and $1 \mathrm{~mm}$ (F10) were selected.

Comparative Study of CPOP and Marketed Sustained Release Tablet: ${ }^{21}$ The comparative study was carried out between marketed formulation 
i.e. Calaptin 120 SR tablet and CPOP by carrying out a dissolution study of the marketed formulation.

\section{RESULTS AND DISCUSSION:}

Evaluation of Osmotic Tablets:

Optimization of Sodium Chloride in Core Tablet: A preliminary trial with $10 \mathrm{mg}$ sodium chloride into the core tablet revealed a slow drug release rate at from the system. The results revealed that incorporating sodium chloride at a concentration of $30 \mathrm{mg} /$ tablet gives the desired drug release rate from $15 \mathrm{mg} / \mathrm{hr}$ during a period of 6 h. Table 5. Further study with a higher concentration of sodium chloride in the core tablet resulted in the bursting of the tablet $(40 \mathrm{mg} \mathrm{NaCl})$. The $30 \mathrm{mg} /$ tablet concentration of sodium chloride was selected as an optimized concentration of osmogen for further study.

TABLE 5: EFFECT OF SODIUM CHLORIDE ON DRUG RELEASE

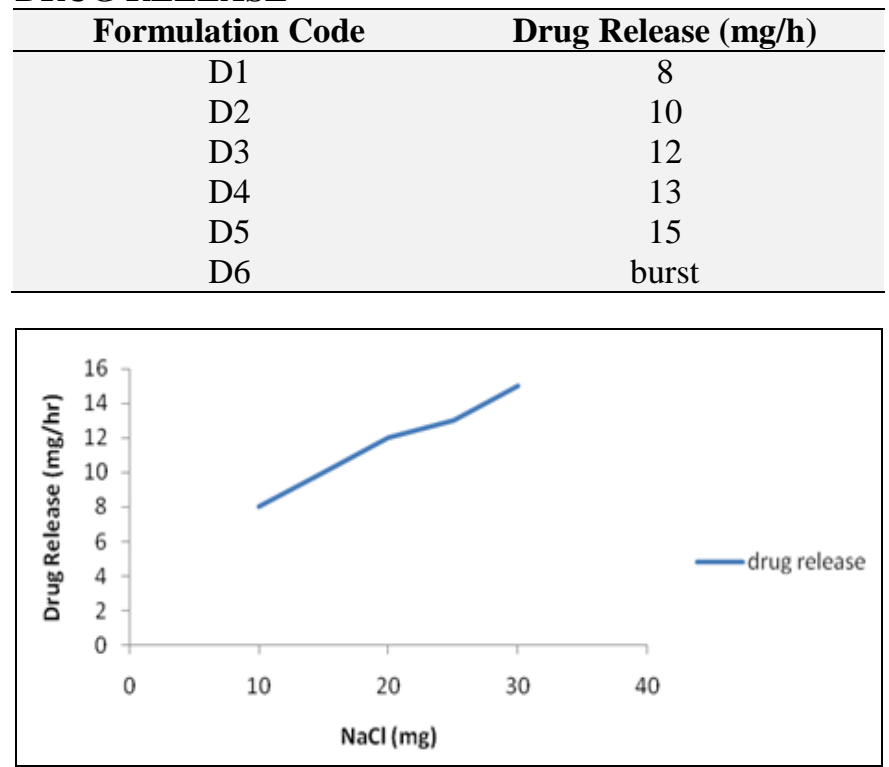

FIG. 1: EFFECT OF SODIUM CHLORIDE ON DRUG RELEASE

Precompression Studies: Many different properties have been employed to assess flowability, of these, angle of repose is the most relevant. The bulk density was found to be between $0.665 \mathrm{gm} / \mathrm{cm}^{3}$. The value indicates a good packing capacity of powder. The tapped density of powder was found to be $0.759 \mathrm{gm} / \mathrm{cm}^{3}$. The bulk density and tapped density was used to calculate the percent compressibility of the powder.

The value of Hausner's ratio was found to be 1.141 , indicating good flowability. Carr's index of was observed 12.36\%, indicating good compressibility of the powder.

Evaluation of Core Tablet: All formulated core tablets were shiny white with a smooth surface, circular curved faced with good texture. The thickness of the core tablet was found to be $5 \mathrm{~mm}$, due to constant tablet press setting irrespective of weight variation.

The hardness of the tablet was found to be in the range of 6 to $7.0 \mathrm{~kg} / \mathrm{cm}^{2}$. This ensured good mechanical strength. The drug content of the tablet was found to be in the range of 99 to $101 \%$.

Evaluation of Consistency of Coat: The consistency of coat was studied by using sodium chloride $(30 \mathrm{mg})$ as an osmogen (excess of osmogen to burst the coat). It was observed that as the $\%$ weight gain increased, the consistency of coat increased, but the drug release decreased Table 6.

\begin{tabular}{ccc} 
TABLE 6: EVALUATION OF CONSISTENCY OF COAT \\
\hline $\begin{array}{c}\text { Formulation } \\
\text { code }\end{array}$ & $\begin{array}{c}\text { Percentage } \\
\text { Release }\end{array}$ & $\begin{array}{c}\text { Coat } \\
\text { Consistency }\end{array}$ \\
\hline D1 & $105.19 \%$ & + \\
D2 & $98.09 \%$ & ++ \\
D3 & $85.65 \%$ & +++ \\
D4 & $69.06 \%$ & +++ \\
D5 & $65.91 \%$ & +++ \\
D6 & $60.30 \%$ & +++ \\
\hline
\end{tabular}

+: Burst, ++: Swell, +++: No change

Evaluation of Effect Different Concentration of Pore Former: Osmotic tablets were subjected to in-vitro drug release studies in the buffer of $\mathrm{pH} 7.5$ for $8 \mathrm{hr}$, the dissolution profiles of all formulations were summarized in Table 7. Hence, it was evident that the increase in the concentration of pore former the drug release from the system was found to be increased.

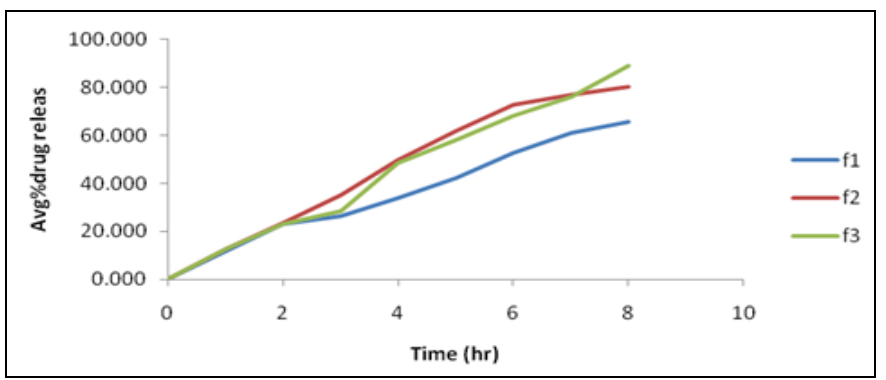

FIG. 2: EFFECT OF DIFFERENT CONCENTRATIONS OF SORBITOL ON DRUG RELEASE FROM CPOP 
TABLE 7: DRUG RELEASE PROFILES OF F1 TO F4

\begin{tabular}{ccccc}
\hline \multirow{2}{*}{$\begin{array}{c}\text { Time } \\
\text { (hrs) }\end{array}$} & \multicolumn{4}{c}{ Avg. \% Drug Release } \\
\cline { 2 - 5 } & F1 & F2 & F3 & F4 \\
\hline 1 & 11.893 & 12.612 & 12.522 & 1.9 \\
2 & 22.919 & 23.642 & 22.833 & 3.0 \\
3 & 26.550 & 35.361 & 28.259 & 4.1 \\
4 & 33.703 & 49.751 & 48.539 & 4.8 \\
5 & 42.153 & 62.063 & 57.970 & 5.1 \\
6 & 52.716 & 72.915 & 68.170 & 6.0 \\
7 & 61.090 & 77.087 & 76.000 & 6.8 \\
8 & 65.646 & 80.383 & 89.082 & 8.4 \\
\hline
\end{tabular}

Kinetics of Drug Release: In the present study, the dissolution was analyzed by PCP Disso Version 2.08 software to study the kinetics of the drug release mechanism. The results showed that some of the formulations followed zero-order dissolution mode, and some followed the Peppas model. The $\mathrm{R}^{2}$ value of all dissolution models was shown in Table 8. The value of $\mathrm{n}$ i.e. release exponent was found in the range of 0.81 to 0.96 , which shoes release of drug from the system by anomalous transport.

TABLE 8: MODEL FITTING OF DIFFERENT FORMULATIONS

\begin{tabular}{cccccccc}
\hline Formulation & \multicolumn{3}{c}{$\mathbf{R}^{\mathbf{2}}$} & \multicolumn{2}{c}{$\mathbf{n}$} & $\mathbf{k}$ \\
\cline { 2 - 6 } code & Zero Order & First Order & Matrix & Peppas & Hixson Crowell & & \\
\hline F1 & 0.9927 & 0.9870 & 0.9525 & 0.9935 & 0.9934 & 0.8149 & 11.83 \\
F2 & 0.9866 & 0.9864 & 0.9519 & 0.9956 & 0.9933 & 0.9360 & 12.79 \\
F3 & 0.9963 & 0.9394 & 0.9920 & 0.9928 & 0.9735 & 0.9645 & 11.81 \\
F4 & 0.9653 & 0.9691 & 0.9742 & 0.9922 & 0.9679 & 0.6517 & 1.959 \\
\hline
\end{tabular}

TABLE 9: EFFECT OF pH ON DRUG RELEASE

\begin{tabular}{cccc}
\hline \multirow{2}{*}{$\begin{array}{c}\text { Time } \\
\text { (hr) }\end{array}$} & \multicolumn{3}{c}{ Average \% drug release } \\
\cline { 2 - 4 } & \multicolumn{3}{c}{ Phosphate Buffer $\mathbf{~ H}$} \\
\cline { 2 - 4 } & $\mathbf{4}$ & $\mathbf{6 . 8}$ & $\mathbf{7 . 5}$ \\
\hline 1 & 12.971 & 12.701 & 12.522 \\
2 & 22.206 & 23.103 & 22.833 \\
3 & 27.899 & 28.442 & 28.259 \\
4 & 48.266 & 48.722 & 48.539 \\
5 & 58.055 & 58.423 & 57.970 \\
6 & 68.436 & 68.536 & 68.170 \\
7 & 75.728 & 75.829 & 76.000 \\
8 & 88.91 & 88.95 & 89.08 \\
\hline
\end{tabular}

*All reading taken in trip

Effect of pH on Drug Release: To study the effect of $\mathrm{pH}$, optimized formulation (F3) was subjected to dissolution studies separately in Phosphate buffer of $\mathrm{pH} 4$ and Phosphate buffer of $\mathrm{pH} 6.8$ for $8 \mathrm{~h}$ as given in Table 9. The system was independent of the $\mathrm{pH}$, as there was no considerable difference in the drug release.

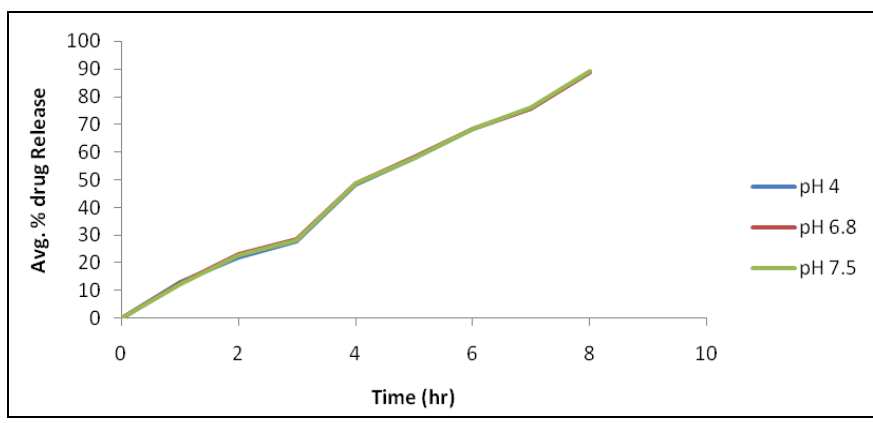

FIG. 3: EFFECT OF DIFFERENT PH ON RELEASE OF DRUG
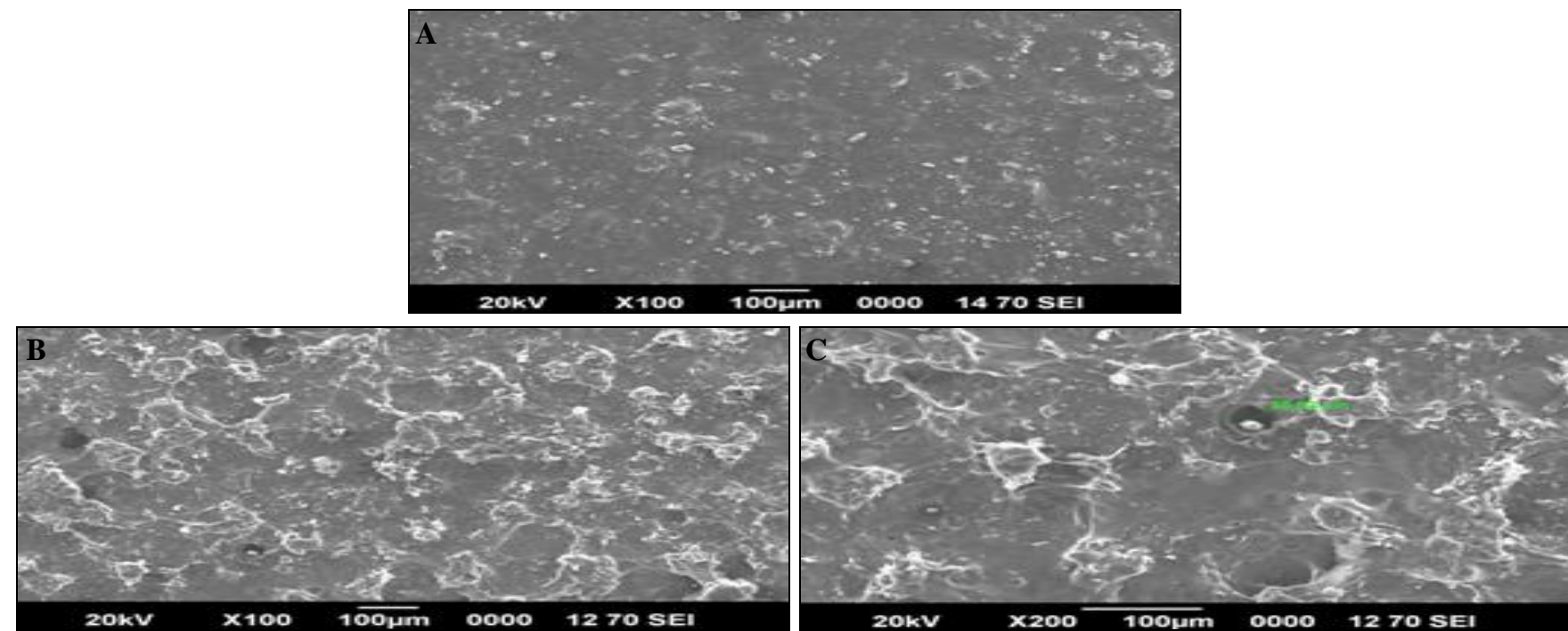

FIG. 4: (A) SEM MICROPHOTOGRAPH (AT 100X MAGNIFICATION) OF VERAPAMIL HCI CPOP TABLET BEFORE DISSOLUTION. (B) SEM MICROPHOTOGRAPH (AT 10OX MAGNIFICATION) OF VERAPAMIL HCI CPOP TABLET AFTER DISSOLUTION. (C) SEM MICROPHOTOGRAPH (AT 200X MAGNIFICATION) OF VERAPAMIL HCI CPOP TABLET AFTER DISSOLUTION SHOWING PORE SIZE 
Surface Morphology Study: To investigate the change in the membrane structure, surface of coated tablets (both before and after dissolution studies) was studied using Scanning Electron microscopy microphotographs showed in Fig. 4 (a, b, c) shows membrane structure before dissolution, initially, the surface of coated tablets was smooth before coming into contact with aqueous environment and coats appeared to be free of pores. A microporous structure of the membrane after dissolution was observed from Fig. 4b, which shows SEM of the membrane after dissolution. This significant porosity has resulted due to leaching of water-soluble additive i.e., sorbitol during dissolution through which drug release takes place. Fig. $\mathbf{4 c}$ shows the pore size.

Stability Study: The optimized formulation F3 was subjected to the accelerated stability study at $40 \pm 2{ }^{\circ} \mathrm{C}$ and $75 \pm 5 \% \mathrm{RH}$ for 3 months as per $\mathrm{ICH}$ guidelines. Drug release profile and visual appearance like dimension, color change, thickness were monitored for 3 months. The results of the accelerated stability studies revealed no significant change in the parameters. From Table 10, the considerable drug loss was not fond for 3 months. Therefore, the formulation of $\mathrm{F} 3$ is considered to be stable.

TABLE 10: STABILITY STUDY

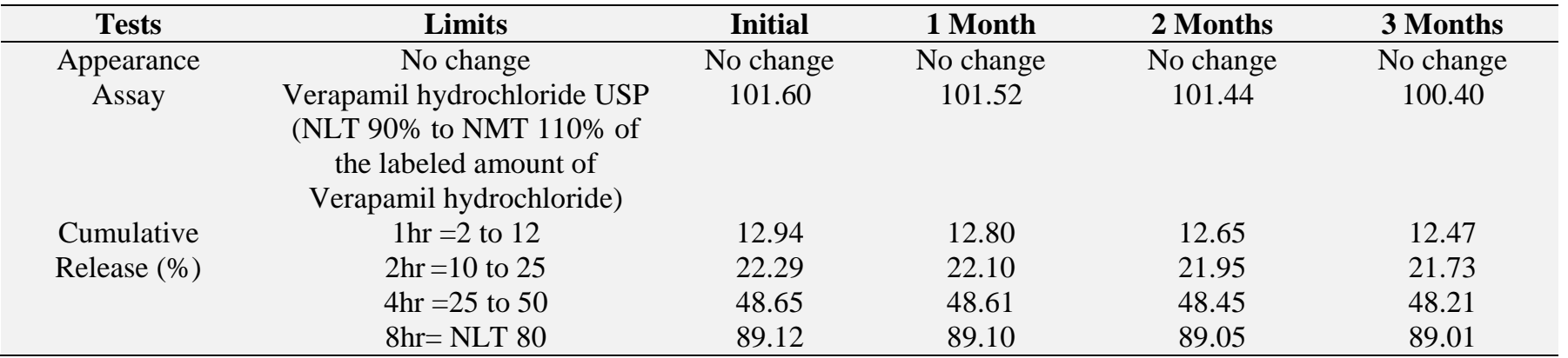

Comparative Study of CPOP and EOP: From the dissolution profile of EOP system Table 11, it was found that formulation F8 having an orifice size $0.5 \mathrm{~mm}$ delivered drug up to $7 \mathrm{~h}$ and formulation F9 (0.8 mm orifice size) for $6 \mathrm{~h}$.

TABLE 11: COMPARATIVE STUDY OF CPOP AND EOP

\begin{tabular}{cccc}
\hline \multirow{2}{*}{$\begin{array}{c}\text { Time } \\
\text { (h) }\end{array}$} & \multicolumn{3}{c}{ Cumulative Drug Release (\%) } \\
\cline { 2 - 4 } & F8 & F9 & F10 \\
\hline 1 & 11.627 & 20.462 & 29.950 \\
2 & 20.80 & 34.245 & 74.212 \\
3 & 53.170 & 69.189 & 92.166 \\
4 & 62.556 & 87.108 & 95.44 \\
5 & 75.025 & 97.195 & 100.07 \\
6 & 89.783 & 100.320 & 100.13 \\
7 & 100.01 & 100.320 & 100.26 \\
8 & 100.04 & 100.320 & 100.26 \\
\hline
\end{tabular}

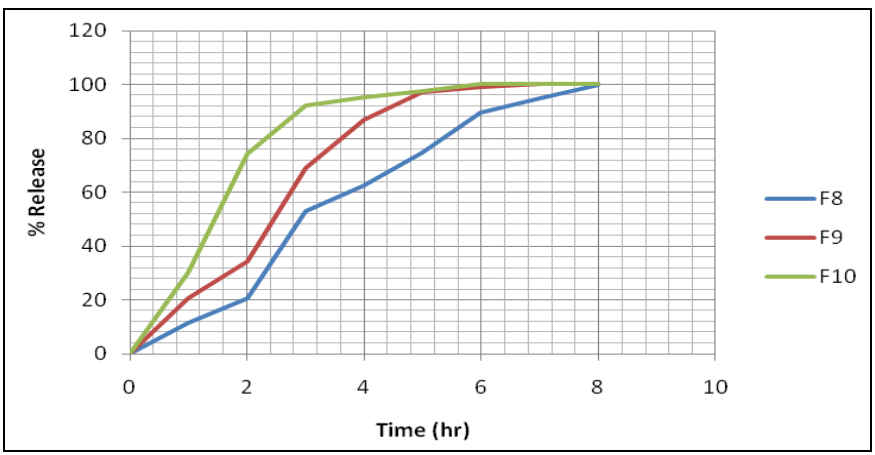

FIG. 5: DISSOLUTION PROFILE OF EOP TABLETS (F8 TO F10)
Formulation F10 with orifice size $1 \mathrm{~mm}$ released 100\% drug within 5 h Fig. 5.

The study revealed that CPOP is superior to conventional EOP, because CPOP delivered Verapamil $\mathrm{HCl}$ for $8 \mathrm{~h}$ and also easier and costeffective to formulate.

\section{Comparative Study of CPOP and Marketed} Sustained Release Tablet: From dissolution studies Table 12, it was revealed that the marketed Verapamil $\mathrm{HCl}$ SR formulation does not follow zero-order drug release pattern as that of CPOP.

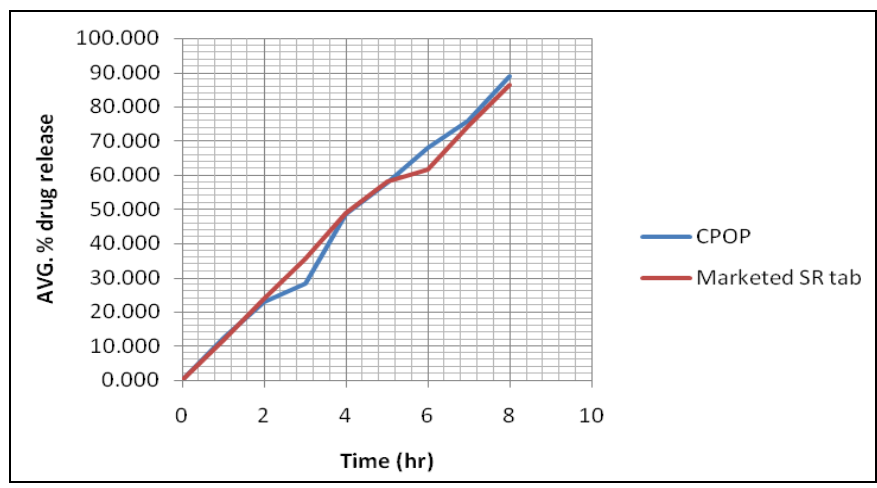

FIG. 6: COMPARATIVE DISSOLUTION PROFILE OF CPOP AND MARKETED SR TABLET 
TABLE 12: COMPARATIVE DISSOLUTION PROFILE OF CPOP AND SR MARKETED TABLET

\begin{tabular}{ccc}
\hline Time h & CPOP & Marketed SR formulation \\
\hline 1 & 12.522 & 11.803 \\
2 & 22.833 & 23.817 \\
3 & 28.259 & 35.448 \\
4 & 48.539 & 48.849 \\
5 & 57.970 & 58.192 \\
6 & 68.170 & 61.476 \\
7 & 76.000 & 74.300 \\
8 & 89.082 & 86.384 \\
\hline
\end{tabular}

CONCLUSION: The investigation carried out so far has encouraged for drawing the following conclusions:

The release of Verapamil $\mathrm{HCl}$ was modulated through the incorporation of an optimized concentration of sodium chloride into the core tablet.

The desired release of Verapamil $\mathrm{HCl}$ from the CPOP was achieved through careful monitoring of the selected formulation variables.

Further, the release from the CPOP studies suggested that the desired consistency of the system could be considered while maintaining the desired release properties of the formulation.

The effect of different pore former in three different concentrations evaluated in the study, which reveals that the sorbitol in the concentration of $25 \% \mathrm{w} / \mathrm{w}$ gives good and desired release as per USP acceptance criteria. It was evident that the increase in the concentration of pore former the drug release from the system was found to be increased.

$>$ From the studies, it was revealed that the F3 is an optimized formulation that was used for further studies and evaluation.

The optimized formulation (F3) delivered Verapamil $\mathrm{HCl}$ independent of $\mathrm{pH}$ and was found to be stable.

ACKNOWLEDGEMENT: We thank all the industries which supplied drug and excipients gift samples. We also are grateful to Pad. Dr. D. Y. Patil College of Pharmacy, Akurdi, Pune, where we worked.

\section{CONFLICTS OF INTEREST: Nil}

\section{REFERENCES:}

1. Mathur M and Mishra R: A review on osmotic pump drug delivery system. International Journal of Pharmaceutical Sciences and Research 2016; 7(2): 453-71.

2. Bansode AS and Sarvanan K: Review on novel osmotic drug delivery system. Journal of Drug Delivery \& Therapeutics 2018; 8(5-s): 87-93.

3. USP- NF, US Pharmacopeia Convention, New York 2005: 3504-08.

4. Sudhamani K: Formulation and evaluation of osmotically controlled release tablets of tramadol hydrochloride. World Journal Of Pharmacy And Pharmaceutical Sciences 2017; 6(7): 1372-87.

5. https://pharmastate.blog/tablet-coating-and-its-differentmethods/

6. Aulton ME: Eds. Pharmaceutics: The Science of Dosage Form Design, Churchill Livingstone: Edinburgh 2005: 133.

7. Sahoo CK, Sahoo TK, Moharana AK and Panda KC: Formulation and optimization of porous osmotic pumpbased controlled release system of residronate sodium for the treatment of postmenopausal osteoporosis. International Journal of Pharmaceutical Sciences Review and Research 2012; 12(1): 118-22.

8. Kumar SU: Formulation and evaluation of sustained release verapamil hydrochloride using natural polymers. International Journal of Applied Pharmaceutical Sciences and Research 2016; 1(2): 76-87.

9. Falguni S, Hitesh J, Viral K and Umesh U: Formulation and evaluation of controlled release osmotic tablet of metoprolol succinate. Asian J Pharm Clin Res 2014; 7(3): 38-43.

10. Pramod K, Singh S and Brahmeshwar M: Development and biopharmaceutical evaluation of extended release formulation of tramadol hydrochloride based on osmotic technology. Acta Pharmaceutica 2009; 59: 15-30.

11. Syed P, Ali S, Omair A, Omer W and Mohammed M: Osmotic drug delivery system of valsartan. International Journal of Research in Pharmaceutical sciences and Technology 2018; 1(2): 43-52.

12. Ghate SK and Sakarkar DM: Development and evaluation of osmotically controlled oral drug delivery system. Indo American Journal of Pharmaceutical Research 2017; 7(09): 459-70.

13. Jain NK: Advances in Controlled and Novel Drug Delivery, 1/e ed. New Delhi: CBS Publishers 2013.

14. Prabakaran D, Singh P, Kanaujia P, Jaganathan KS, Rawat A and Vyas SP: Modified push-pull osmotic system for simultaneous delivery of theophylline and salbutamol: development and in-vitro characterization. International Journal of Pharmaceutics 2004; 284: 95-108

15. ICH Harmonized Tripartite Guidelines, Validation of Analytical Procedures, Text and Methodology, Q2 (R1), 2005.

16. Khar RK: Tageteted \& controlled drug delivery novel carrier systems. $1^{\text {st }}$ ed. New Delhi: CBS Publishers 2012; 234.

17. Sadhana RS, Nityanand SZ, Bhushan G, Shantanu S and Shivram BS: Design and development of controlled porosity osmotic tablet of diltiazem hydrochloride. J Adv Pharm Technol Res 2012; 3(4): 229-36.

18. Patrick $J$ and Martins: Physical Pharmacy and Pharmaceutical Sciences, $5^{\text {th }}$ ed, Lippincott, Williams \& Wilkins 2006: 135-37. 
19. Bhatt PP: Osmotic drug delivery systems for poorly soluble drugs. The Drug Delivery Companies Report Autumn/Winter 2004.

20. Vidyadhara S, Sasidhar R, Uma MV, Sundeep M and Showribabu C: Formulation and evaluation of losartan potassium osmotic controlled matrix tablets. Indian
Journal of Pharmaceutical Education and Research 2014; 48: $18-26$.

21. Khatri N, Nikam S and Bilandi A: Oral osmotic drug delivery system: a review. Int J Pharm Sci Res 2016; 7(6): 2302-12.

How to cite this article:

Shivnikar MA and Bhong PN: Formulation and evaluation of controlled porosity osmotic tablet of verapamil hydrochloride. Int J Pharm Sci \& Res 2020; 11(6): 2976-83. doi: 10.13040/IJPSR.0975-8232.11(6).2976-83.

All @ 2013 are reserved by the International Journal of Pharmaceutical Sciences and Research. This Journal licensed under a Creative Commons Attribution-NonCommercial-ShareAlike 3.0 Unported License.

This article can be downloaded to Android OS based mobile. Scan QR Code using Code/Bar Scanner from your mobile. (Scanners are available on Google Play store) 